\title{
Mortalidade infantil em uma capital do norte do Brasil: estudo de série temporal
}

\author{
Child mortality in a capital of northern Brazil: temporal series study \\ Mortalidad infantil en una capital del norte de Brasil: estudio serie temporal
}

Jeanne Lúcia Gadelha Freitas ${ }^{1 *}$, Kátia Fernanda Alves Moreira ${ }^{1}$, Priscilla Perez da Silva Pereira ${ }^{1}$, Marcos Antônio Sales Rodrigues ${ }^{1}$, Camila Pardo Dala Riva ${ }^{1}$, André Lucas Santana Barbosa ${ }^{1}$, Edson dos Santos Farias ${ }^{1}$.

\section{RESUMO}

Objetivo: Caracterizar e identificar causas de mortalidade infantil em Porto Velho, Rondônia de 2012 a 2017. Métodos: Série temporal com dados do Sistema de Informação sobre Mortalidade e Sistema de Informações sobre Nascidos Vivos. As frequências e o coeficiente foram realizadas pelo software SPSS Statistics, versão 17. Resultados: Dos 53.321 nascidos vivos, $1,31 \%$ vieram a óbitos antes de completar um ano de vida. Destes, $48,93 \%$ ocorreram no período neonatal precoce e $56,78 \%$ foram por causas não claramente evitáveis. As maiores causas de óbitos foram associadas às ações com adequada atenção ao feto e recém-nascido $(46,50 \%)$ e à mulher na gestação $(32,87 \%)$. A principal causa de óbitos neonatais foi por septicemia bacteriana não especificada no recém-nascido $(57,73 \%)$. O maior coeficiente de mortalidade Infantil foi em 2016 (14,82 óbitos/1.000 nascidos vivos). Conclusão: O óbito infantil no período neonatal precoce ocorreu por causas evitáveis ligadas à atenção ao feto/recém-nascido e à gestante. A mortalidade neonatal por septicemia bacteriana não especificada reflete falhas no pré-natal/parto/pós-nascimento. É imprescindível qualificar profissionais que atuam no ciclo gravídico-puerperal, sobretudo médicos responsáveis pelas notificações para melhorar a vigilância do óbito infantil. Sugere-se avaliar fatores que interferem na qualidade do pré-natal e na assistência realizada no momento do parto.

Palavras-chave: Mortalidade infantil, Criança, Assistência à saúde da mãe e da criança.

\section{ABSTRACT}

Objective: To characterize and identify causes of infant mortality in Porto Velho, Rondônia from 2012 to 2017. Methods: Time series with data from the Mortality Information System and the Live Birth Information System. The frequencies and coefficients were performed using the SPSS Statistics software, version 17. Results: Of the 53,321 live births, $1.31 \%$ resulted in deaths before completing one year of life. Of these, $48.93 \%$ occurred in the early neonatal period and $56.78 \%$ were certainly not preventable. The main causes of death associated with actions with attention to the newborn fetus $(46.50 \%)$ and women during pregnancy $(32.87 \%)$. The main cause of neonatal deaths was due to non-prime bacterial septicemia in the newborn (57.73\%). The highest infant mortality rate was in 2016 (14.82 deaths / 1,000 live births). Conclusion: Infant death in the early neonatal period occurred due to preventable causes linked to care for the fetus / newborn and the pregnant woman. Neonatal mortality from bacterial septicemia does not satisfy prenatal / delivery / post-birth failures. It is essential to qualify professionals who work in the pregnancy-puerperal cycle, especially doctors responsible for notifications to improve the surveillance of infant death. It is suggested to evaluate factors that interfere with the quality of prenatal care and the analysis performed at the time of delivery.

Keywords: Infant mortality, Child, Mother and child health assistance.

\section{RESUMEN}

Objetivo: Caracterizar e identificar las causas de mortalidad infantil en Porto Velho, Rondônia de 2012 a 2017. Métodos: Series de tiempo con datos del Sistema de Información de Mortalidad y el Sistema de Información de Nacidos Vivos. Las frecuencias y el coeficiente se realizaron mediante el software SPSS Statistics, versión 17. Resultados: De los 53.321 nacidos vivos, el 1,31\% falleció antes de cumplir un año de vida. De éstos, el $48,93 \%$ se produjo en el período neonatal temprano y el $56,78 \%$ se debió a causas que no son claramente prevenibles. Las principales causas de muerte se asociaron a acciones de atención adecuada

1 Universidade Federal de Rondônia (UNIR), Porto Velho - RO. *E-mail: jeannegadelha@unir.br 
al feto y recién nacido $(46,50 \%)$ y a la mujer durante el embarazo $(32,87 \%)$. La principal causa de muerte neonatal fue la septicemia bacteriana no especificada en el recién nacido $(57,73 \%)$. La tasa de mortalidad infantil más alta se registró en 2016 (14,82 muertes / 1.000 nacidos vivos). Conclusión: La muerte infantil en el período neonatal temprano ocurrió por causas prevenibles vinculadas al cuidado del feto / recién nacido y la gestante. La mortalidad neonatal por septicemia bacteriana no satisface las fallas prenatales / del parto / posparto. Es fundamental capacitar a los profesionales que laboran en el ciclo embarazo-puerperal, especialmente a los médicos encargados de las notificaciones para mejorar la vigilancia de la muerte infantil. Se sugiere evaluar los factores que interfieren con la calidad de la atención prenatal y el análisis realizado al momento del parto.

Palabras clave: Mortalidad infantil, Niño, Asistencia de salud maternoinfantil.

\section{INTRODUÇÃO}

Entre os indicadores de mortalidade específicos, o Coeficiente de Mortalidade Infantil (CMI) é o que melhor estima o risco de crianças Nascidas Vivas (NV) virem a óbitos antes dos doze meses de vida. (ONU, 2015; BRASIL, 2016).

Além de excelente indicador de saúde de uma população, o CMI acompanha o desenvolvimento e a qualidade de vida de uma nação, pois retrata a eficácia de políticas de saúde pública destinada às crianças nos primeiros dias de vida (UNICEF, 2019). Em vista do impacto da Mortalidade Infantil (MI), até 2030, a meta mundial é reduzir as mortes neonatais para 12/1.000 NV e de crianças menores de cinco anos para 25 óbitos/1.000 nascidos vivos (ONU, 2015; GBD, 2016).

O monitoramento da Mortalidade Infantil (MI) baseia-se na idade do óbito da criança e nas diferentes causas de mortes em cada período (ONU, 2015). Conforme estes critérios, a MI então é composta de: período mortalidade neonatal (óbitos de 0 a 27 dias de vida) e pós-neonatal (28 dias a um ano). A mortalidade neonatal (MN) subdivide-se em período neonatal precoce ( 0 a 6 dias completos de vida) e neonatal tardio ( 7 a 27 dias de vida) (MIGOTO MT, et al., 2018).

Segundo o Fundo nas Nações Unidas para a Infância e a Organização Mundial de Saúde, até 2018, em todo mundo cerca de 5,3 milhões morrerem antes de completar cinco anos de vida por causas evitáveis com cuidados básicos de saúde. No mesmo ano, a taxa de mortalidade neonatal foi 17,19/1.000 NV e a mortalidade pós-neonatal foi de 11/1.000 NV (ONU, 2015; OMS, 2016).

No Brasil, a redução no $\mathrm{CMI}$ tem sido reflexo de políticas públicas de saúde no combate às doenças infecto-parasitárias e respiratórias e a desnutrição (MAIA LTS, et al., 2020). De 2000 a 2015, por exemplo, a taxa do CMI geral diminuiu de 29,02 para 13,82/1.000 nascidos vivos (IBGE, 2020). No período pós-neonatal, de 1990 a 2012, ocorreu redução expressiva do CMI de 47,1 para 14,6 óbitos/1.000 NV em especial no período neonatal precoce (CALDAS ADR, et al., 2017).

Embora estes avanços tenham ocorrido em algumas regiões do país, a taxa de mortalidade neonatal precoce manteve-se elevada tendo como causas principais a prematuridade, asfixia, baixo peso ao nascer do RN, idade gestacional bem como as anomalias e doenças infecciosas no recém-nascido (SARTORELLI AP, et al., 2017; FRANÇA EB, et al., 2017).

Com estas taxas, a média do CMI no país é cerca de cinco vezes mais elevado que países desenvolvidos como o Japão (3 óbitos/1.000 NV) e a Alemanha (4 óbitos/1.000 NV) (BRASIL, 2016, UNICEF, 2019). Mais da metade das mortes de crianças brasileiras poderiam ter sido evitadas com adequada atenção à mulher no pré-natal, parto e ao recém-nascido desafiando a saúde pública no Brasil e no mundo (LANSKY S, et al., 2014; WANG H, et al., 2014; CASTRO ECM, 2016).

A evitabilidade da Ml exige além de melhorias socioeconômicas, sanitárias e de acesso aos serviços de saúde, a qualificação da atenção no pré-natal e parto e aos recém-nascidos, particularmente os prematuros e com baixo peso (LIMA JC, et al., 2017; RÊGO MGS, et al., 2018). Ademais, as iniquidades socioeconômicas contribuem com disparidades nos índices de CMI entre diferentes contextos do país. Na região norte do país, as taxas segue alta $(20,97$ óbitos/1000 NV) se comparadas à região Sul $(11,58 / 1.000 \mathrm{NV})$ e à média nacional 
(17,0 óbitos/1.000 NV). (FRANÇA EB, et al., 2017). No estado de Rondônia o CMl é elevado (14,8 óbitos/1.000 NV) se comparado aos demais estados brasileiros (FRANÇA EB, et al., 2017).

Em Porto Velho, cidade do presente estudo, a taxa de CMI em 2006 a 2010, foi de 21/1.000 nascidos vivos, superior à taxa nacional $(15,7 / 1.000 \mathrm{NV})$ no mesmo período. Entre as causas evitáveis, estiveram as mortes por falhas na assistência no pré-natal, parto e ao recém-nascido (MOREIRA KFA, et al., 2014).

Isto posto, esta investigação é relevante, pois amplia as análises anteriores sobre a mortalidade infantil local, sendo indispensável para subsidiar a gestão de saúde no planejamento de ações baseadas em evidências para melhoria dos indicadores perinatais e, consequentemente diminuir a mortalidade infantil no município. O presente estudo teve como objetivo caracterizar e identificar causas de mortalidade infantil no município de Porto Velho, Rondônia, entre 2012 a 2017.

\section{MÉTODOS}

Estudo de série temporal, utilizando dados secundários do Sistema de Informação sobre Mortalidade (SIM) e do Sistema de Informações sobre Nascidos Vivos (SINASC), acessados na plataforma do Departamento de Informática do SUS (DATASUS) relativo ao recorte temporal de 01 de janeiro de 2012 a 31 de dezembro de 2017. A coleta, extração e análise de dados ocorreram em maio de 2019.

O município de Porto Velho, a capital do estado de Rondônia, situa-se na região Norte do país, possui um Índice de Desenvolvimento Humano (IDH) de 0,736, uma população estimada para 2019 em torno de 529.544 habitantes. Em 2015, ano final da série analisada, a Taxa de Mortalidade Infantil (TMI) foi de 14,75 óbitos por mil nascidos vivos, ocupando a 19 ำ posição entre os 52 municípios do estado e a $2190^{\circ}$ posição em relação ao país (IBGE, 2020).

As informações compõem os registros de óbitos em menores de um ano, agrupadas por componentes (neonatal, pós-neonatal) por sua vez, subdividido em óbito precoce e óbito neonatal tardio (DIAS BAS, et al., 2017). Na análise por grupo de causas, foi utilizada a lista de causas de mortes evitáveis por intervenções do Sistema Único de Saúde do Brasil e dados adicionais sobre partos e nascimentos pela relação direta com óbitos infantis (MALTA DC, et al., 2010).

Foram selecionadas as Autorizações de Internação Hospitalar (AlH) com preenchimento completo e legível, com diagnóstico principal/secundário, conforme a Classificação Estatística Internacional de Doenças e Problemas Relacionados à Saúde - 10ª Revisão (CID-10) da Organização Mundial de Saúde de 1997.

A caracterização das variáveis sociodemográficas foram: idade materna $(\leq 20,21$ a 34 anos, $35 \geq$ e ignorados), escolaridade materna (nenhuma, 1 a 3 anos, 4 a 7 anos, 8 a 11 anos, $\geq 12$ anos e ignorados), idade gestacional (pré-termo, atermo, pós-termo e ignorado) e peso ao nascer ( $<2500 \mathrm{~g}, \geq 2500 \mathrm{~g}$ e ignorado); óbitos infantis (neonatal precoce, tardio, pós-neonatal e ignorado), causa básica do óbito (evitáveis, mal definidas e não claramente evitáveis); causas evitáveis (ações de imunoprevenção, adequada atenção à mulher na gestação, adequada atenção à mulher no parto, adequada atenção ao feto e recém-nascido, ações adequadas de diagnóstico de tratamento e ações adequadas de promoção a saúde vinculadas de ações adequadas de atenção a saúde); mortalidade/critérios de evitabilidade (Septicemia bacteriana não especificada no RN, Síndrome da angústia respiratória do RN, Aspiração neonatal de mecônio, Septicemia bacteriana não especificada no RN, Síndrome da angústia respiratória do RN, Diarreia ou gastroenterite por origem infecciosa presumível e demais causas).

Para o cálculo do Coeficiente de Mortalidade infantil, utilizou-se a equação: $\mathrm{CMI}=$ número de óbitos total por tipo no ano específico, dividido pela população total de interesse, na mesma área e ano, multiplicado por 1.000. Após coleta, os dados tiveram dupla entrada em planilha e validada posteriormente, seguida da análise de distribuição de frequências absolutas e relativas, apresentadas em formato de tabelas e figuras. $O$ programa utilizado foi Statistical Package for the Social Science (SPSS), versão 17.

O estudo é vinculado ao subprojeto "Morbidades em Porto Velho" constitutivo do projeto matriz intitulado "Estudo sobre morbidades em Rondônia: a assistência, a formação e o ensino em saúde em discussão", aprovado pelo CEP/UNIR sob a CAAE: 85533318.9.0000.5300 sob o parecer $n^{\circ} 2.548 .115$. 


\section{RESULTADOS}

No período analisado, dos 53.321 nascidos vivos, cerca de $1,31 \%(n=701)$ foram a óbitos antes de completar um ano de vida, conforme demonstra a distribuição de frequências relativas (\%) de óbitos de 2012 a 2017 nos triênios analisados (Figura 1).

O maior número de óbitos ocorreu nos anos intercalados de 2012 (17,97\%) e 2016 (17,83\%) com redução gradativa de mortes no período de 2013 a 2015, com frequências entre $16,41 \%$ a 16,12\% respectivamente. Em 2017, último ano da série analisada, ocorreu uma queda significativa no número de óbito infantil (15,55\%).

Figura 1 - Distribuição das frequências relativas (\%) de mortalidade infantil de 2012 a 2017, segundo triênios (2012 a 2014/2015 a 2017), Porto Velho, Rondônia, 2019 ( $n=701)$.

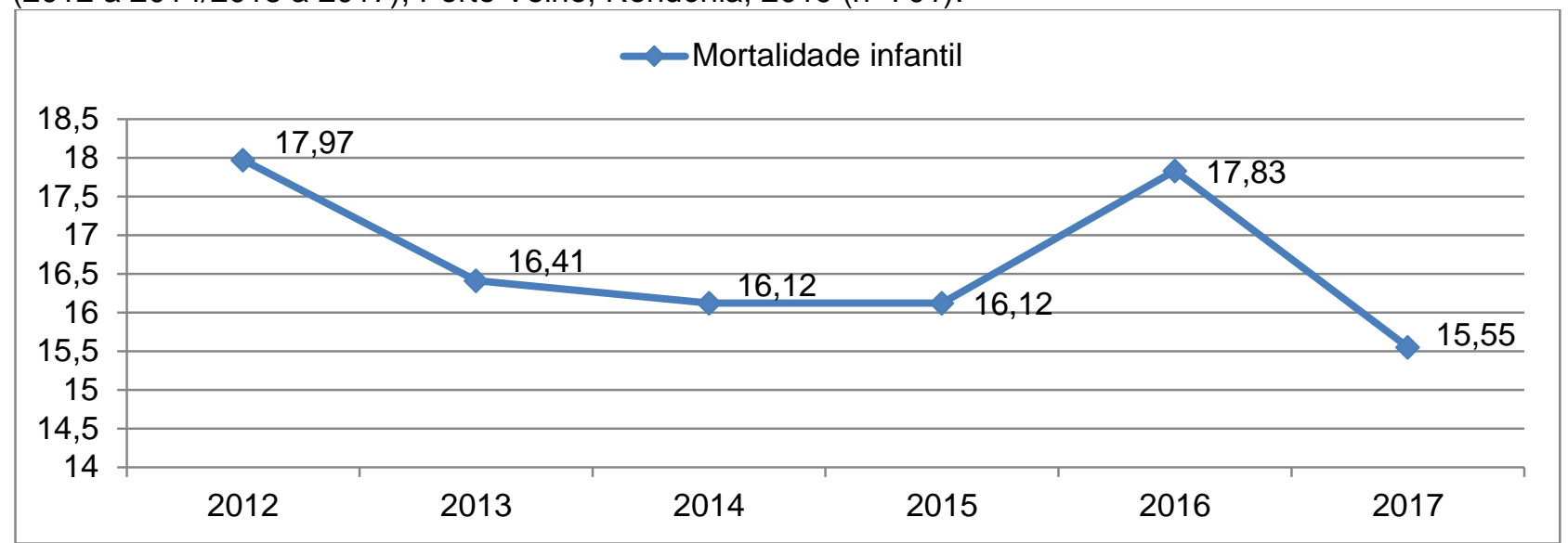

Fonte: Freitas JLG, et al., 2020. Baseado em Sistema de Informações sobre Mortalidade (SIM), 2019.

A distribuição proporcional do Coeficiente de Mortalidade Infantil (CMI) no período avaliado, mostra que as maiores taxas ocorreram nos anos intercalados de 2012 (14,42 por $1.000 \mathrm{NV})$ e 2016 (14,82 por $1.000 \mathrm{NV})$ A menor taxa de CMI foi em 2013 (11,8 por 1.000 NV) (Figura 2).

Figura 2 - Distribuição proporcional do Coeficiente de Mortalidade Infantil em menores de um ano, período de 2012-2017, segundo número de óbitos por 1.000 NV, Porto Velho, Rondônia, $2019(\mathrm{n}=701)$.

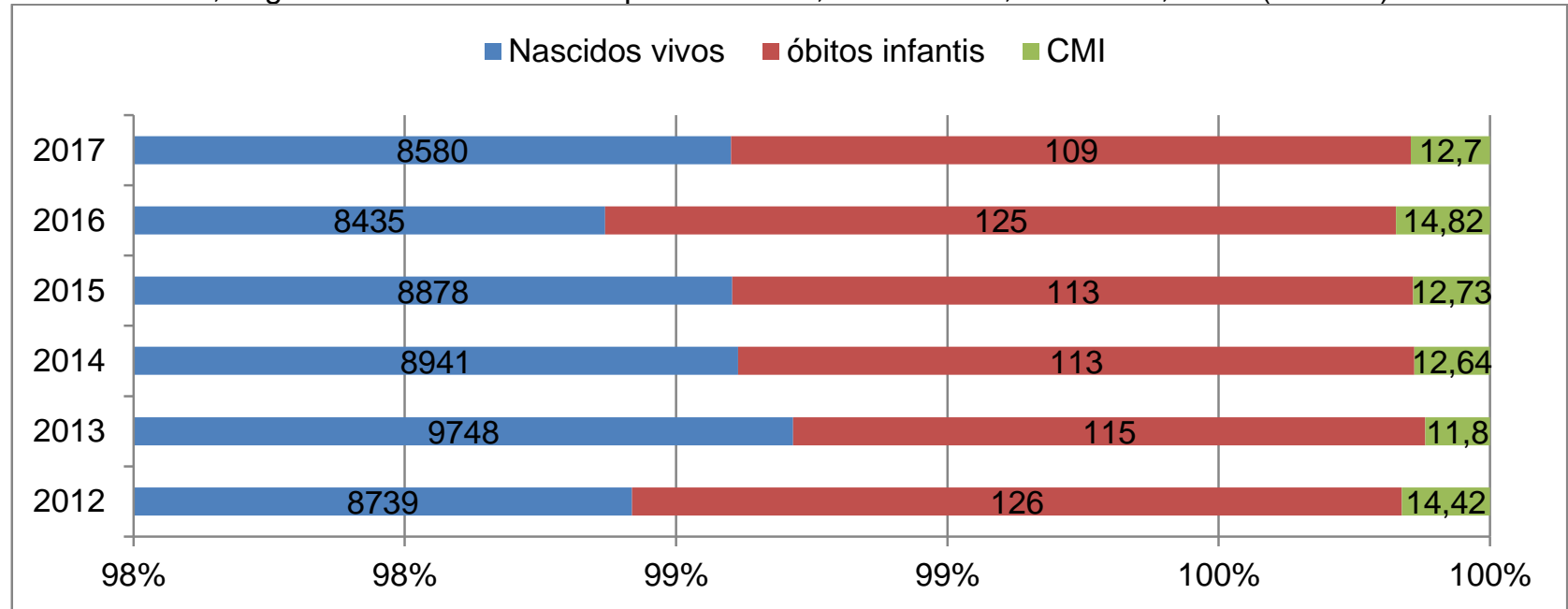

Fonte: Freitas JLG, et al., 2020. Baseado em Sistema de Informações sobre Mortalidade (SIM), 2019.

As características sociodemográficas da mãe, a idade gestacional e peso das crianças que vieram a óbito antes de completar um ano, indica que, quase metade das mães tinham entre 21 a 34 anos $(46,79 \%)$, parcela expressiva com escolaridade ignorada $(29,24 \%)$ ou apenas com oito a 11 anos de estudo $(25,11 \%)$. Mais da metade das crianças nasceram com idade gestacional pré-termo $(53,64 \%)$ e peso menor que $2.500 \mathrm{~g}(62,05 \%)$ (Tabela 1). 
Tabela 1 - Características sociodemográficas da mãe, idade gestacional e peso das crianças relacionado à mortalidade infantil, período 2012 a 2017, Porto Velho, Rondônia, 2019.

\begin{tabular}{|c|c|c|}
\hline Variáveis & $n=701$ & $\%$ \\
\hline \multicolumn{3}{|l|}{ Idade materna } \\
\hline$\leq 20$ & 181 & 25,82 \\
\hline 21 a 34 anos & 328 & 46,79 \\
\hline $35 \geq$ & 52 & 7,42 \\
\hline Ignorados & 140 & 19,97 \\
\hline \multicolumn{3}{|c|}{ Escolaridade materna } \\
\hline Nenhuma & 80 & 11,41 \\
\hline 1 a 3 anos & 49 & 6,99 \\
\hline 4 a 7 anos & 120 & 17,12 \\
\hline 8 a 11 anos & 176 & 25,11 \\
\hline$\geq 12$ anos & 71 & 10,13 \\
\hline Ignorados & 205 & 29,24 \\
\hline \multicolumn{3}{|c|}{ Idade gestacional } \\
\hline Pré-termo & 376 & 53,64 \\
\hline Atermo & 144 & 20,54 \\
\hline Pós-termo & 1 & 0,14 \\
\hline Ignorado & 180 & 25,68 \\
\hline \multicolumn{3}{|l|}{ Peso ao nascer } \\
\hline$<2500 \mathrm{~g}$ & 435 & 62,05 \\
\hline$\geq 2500 \mathrm{~g}$ & 178 & 25,39 \\
\hline Ignorado & 88 & 12,56 \\
\hline
\end{tabular}

Fonte: Freitas JLG, et al., 2020. Baseado em Sistema de Informações sobre Mortalidade (SIM), 2019.

A caracterização das causas básica de óbitos infantis segundo período de nascimento e as causas evitáveis demonstra que, quase metade dos óbitos ocorreram no período neonatal precoce (48,93\%) e mais da metade dos óbitos foram relacionados a causas não claramente evitáveis $(56,78 \%)$.

Os óbitos por causas evitáveis foram ligados às ações com adequada atenção ao feto e recém-nascido $(46,50 \%)$ e à mulher na gestação $(32,87 \%)$ e juntas, responderam por quase a totalidade dos óbitos evitáveis (79,37\%) (Tabela 2).

Tabela 2 - Caracterização dos óbitos infantis em crianças menores de um ano, segundo períodos e causas evitáveis, 2012 a 2017, Porto Velho, Rondônia, 2019.

\begin{tabular}{lcc}
\hline Variáveis & $\mathbf{n}=\mathbf{7 0 1}$ & $\%$ \\
\hline Óbitos infantis & & 48,93 \\
\hline Neonatal precoce & 343 & 15,69 \\
Neonatal tardio & 110 & 34,52 \\
Pós-neonatal & 242 & 0,86 \\
lgnorado & 6 & 40,80 \\
\hline Causa básica do óbito (n=701) & & 2,42 \\
\hline Evitáveis & 286 & 56,78 \\
Mal definidas & 17 & 0,00 \\
Não claramente evitáveis & 398 & 32,87 \\
\hline Causas Evitáveis & $\mathbf{n = 2 8 6}$ & 8,39 \\
\hline Ações de imunoprevenção & 0 & 46,50 \\
Adequada atenção à mulher na gestação & 94 & 0,70 \\
Adequada atenção à mulher no parto & 24 & 11,54 \\
Adequada atenção ao feto e recém-nascido & 133 & 2 \\
Ações adequadas de diagnóstico de tratamento & 2 & \\
Ações adequadas de promoção a saúde vinculadas de & 33 & \\
ações adequadas de atenção a saúde & & \\
\hline
\end{tabular}

Fonte: Freitas JLG, et al., 2020. Baseado em Sistema de Informações sobre Mortalidade (SIM), 2019. 
Os achados das principais causas de mortalidade, segundo os critérios de evitabilidade por triênios na série analisada, indica que nos dois períodos avaliados, a maior causa de óbitos foi por septicemia bacteriana não especificada no recém-nascido. De 2012 a 2014 e de 2015 a 2017, esta causa representou, respectivamente $45,28 \%$ e $57,73 \%$ dos óbitos. Do total de registros $(n=203)$ houve redução de $4 \%(n=9)$ no número de óbitos entre os dois triênios (Tabela 3).

Tabela 3 - Principais causas de mortalidade em menores de um ano, segundo critérios de evitabilidade e triênios (2012-2014 e 2015-2017) Porto Velho, Rondônia, 2019.

\begin{tabular}{lll}
\hline Variáveis & $\mathbf{n = 2 0 3}$ & $\%$ \\
\hline Mortalidade/critérios de evitabilidade & $(\mathbf{n = 1 0 6 )}$ & \\
\hline Período de 2012 a 2014 & 48 & 45,28 \\
\hline Septicemia bacteriana não especificada no RN & 38 & 35,85 \\
Síndrome da angústia respiratória do RN & 20 & 18,87 \\
Aspiração neonatal de mecônio & $\mathbf{( n = 9 7 )}$ & \\
\hline Período de 2015 a 2017 & 56 & 57,73 \\
\hline Septicemia bacteriana não especificada no RN & 33 & 34,02 \\
Síndrome da angústia respiratória do RN & 8 & 8,24 \\
Diarreia/gastroenterite de origem infecciosa presumível &
\end{tabular}

Fonte: Freitas JLG, et al., 2020. Baseado em Sistema de Informações sobre Mortalidade (SIM), 2019.

\section{DISCUSSÃO}

Em Porto Velho, as mortes em menores de um ano, se concentraram em anos intercalados (2012-2016) com percentuais semelhantes entre si $(17,97 \%$ e $17,83 \%)$, mas com redução nos demais anos, chegando a 15,55\% em 2017. Esse achado faz parte da evolução e dinâmica da mortalidade infantil no Brasil, ocorrido entre 1990 a 2015, quando o país obteve uma redução de 67,6\% dos óbitos em menores de um ano, cumprindo o quarto dos seis objetivos do milênio (UNICEF e OMS, 2015; FRANÇA EB, et al., 2017).

Essa expressiva redução foi graças ao conjunto de ações de promoção e proteção à saúde das crianças brasileiras, a exemplo do Programa Nacional de Imunização, do incentivo ao aleitamento materno, dos bancos de leite, da atenção humanizada à gravidez, parto e puerpério, assegurando o nascimento e crescimento seguro das crianças (BRASIL, 2015; VIDAL E SOUZA SMC, et al., 2018). A despeito desses avanços, sabese que regiões socioeconômicas menos favorecidas, como o Norte e Nordeste do país, apresentam maiores riscos para o óbito de crianças nos seus primeiros dias de vida (OLIVEIRA MND, et al., 2017; LIMA JC, et al., 2017; MAIA LTS, et al., 2020).

Nesse estudo, o aumento de óbitos em 2016, culmina com a elevação no percentual dos óbitos em menores um ano, em relação ao ano de 2015 em nível nacional. Esse aumento pode ser explicado pela retração no número de Nascidos vivos nesse intervalo de tempo, com o maior índice de óbitos no período pós-neonatal, tendo como causa básica, o aumento de diarreias em todas as regiões do país, exceto a região sul (ABRASCO, 2018).

Também nesse estudo, o maior CMI recaiu em anos intercalados (2012-2016) com taxas próximas entre si, mas com destaque em 2016, quando o município teve o CMI de 14,82 óbitos/1.000 NV. Nesse mesmo ano, o estado de Rondônia, junto com Maranhão e Amapá, tiveram CMI de 20,0 óbitos/1.000 NV bem acima da taxa de CMI nacional (13,3/1000NV) (IBGE, 2016). Como se pode ver, embora o Brasil tenha superado à meta traçada pela OMS (15,7 óbitos/1.000 NV) persistem discrepâncias nas taxas de CMI em regiões menos desenvolvidas que precisam ser superadas (ALKEMA L, et al., 2014; OMS; UNICEF, 2015).

Sabe-se que o CMI sofre impacto direito de determinantes sociais de uma região, pois exerce um efeito protetor à medida que alerta para a evitabilidade dos óbitos em crianças menores de um ano (MAIA LTS, et al., 2020). Estudo de coorte nacional em 2012 com 7.887 nascimentos demonstrou a importância dessas variáveis sociais e do nível de assistência à saúde com boa qualidade na redução da mortalidade infantil (KROPIWIEC MV, et al., 2017). 
No presente estudo, quase metade das mães eram jovens, com escolaridade entre oito a 11 anos de estudo. Mais da metade das crianças nasceram com idade gestacional pré-termo e peso menor que $2.500 \mathrm{~g}$. Perfil semelhante foi encontrado nas regiões Norte/Nordeste e no vale do Jequitinhonha, sudeste do país, onde os óbitos infantis em menores de um ano foram predominantes em mães jovens (20-34 anos) ainda que sem associação com o desfecho dos óbitos. Por outro lado, nesse mesmo estudo, o nível de escolaridade materno foi inferior a oito anos de estudo e esteve associado à mortalidade dos óbitos avaliados (BATISTA CB, et al., 2018).

Outros fatores são evidenciados na literatura como determinantes para sobrevida em menores de um ano, especialmente no período neonatal. Estudos revelam que o peso abaixo de $2.500 \mathrm{~g}$ e o nascimento antes de 37 semanas de gestação, estão associados ao óbito infantil e 56\% destes eram evitáveis, sendo a maioria reduzíveis por atenção adequada à mulher na gestação (SARTORRELI AP, et al., 2017). Diferentes estudos ressaltam a influência de questões como o acesso e a qualidade do pré-natal, condições socioeconômicas maternas como fatores sobre as condições de vida intrauterina, gestação e nascimento, sobretudo em regiões como Norte e Nordeste do país (BATISTA CB, et al., 2018; VIDAL E SILVA SMC, et al., 2018; VILANOVA CS, et al., 2019; MAIA LTS, et al., 2020).

Quase metade dos óbitos infantis em Porto Velho ocorreu no período neonatal precoce (48,93\%), porém mais da metade destes foram relacionados às causas não claramente evitáveis ( $56,78 \%)$. O óbitos por causas evitáveis, foram associados às ações com adequada atenção ao feto e recém-nascido e à mulher na gestação e juntas, responderam pela quase totalidade dos óbitos evitáveis $(79,37 \%)$. O óbito neonatal precoce reflete uma estreita relação entre a saúde do recém-nascido e uma atenção adequada à gestante com um pré-natal de qualidade.

Estudo na cidade Maceió, Alagoas, apresentou que o CMI no período neonatal esteve diretamente ligado à fragilidade e irregularidade da assistência de pré-natal, gestação, parto e nascimento (FILHO ACAA, et al., 2017). Análise de tendência do óbito infantil em Recife, Pernambuco, de 1980 a 2012, identificou que 80\% dos óbitos foram por causas evitáveis e destes, 51,3\% eram reduzíveis por adequada atenção à mulher na gestação (OLIVEIRA CM, et al., 2016).

São causas que refletem as fragilidades na rede de cuidado materno-infantil como a baixa capacitação dos profissionais para identificar oportunamente problemas evitáveis no âmbito da atenção básica (DIAS BAS, et al., 2017). Além deste, tem sido apontados à qualificação de profissionais para o manejo obstétrico adequado bem como da reanimação neonatal, aumento do acesso a cuidados intensivos neonatais após o parto, frente às intercorrências com o feto durante o trabalho de parto e parto (FRANÇA EB, et al., 2017; MALTA DC, et al., 2019).

Nos dois triênios avaliados, a maior causa de óbitos foi por septicemia bacteriana não especificada no recém-nascido. No último triênio (2015 a 2017) esta causa representou 57,73\% dos óbitos. Em diferentes investigações sobre Mortalidade Infantil no Brasil e no mundo, as mortes evitáveis são provocadas por afecções originárias no período perinatal (20 semanas de gestação até seis dias) e até os 27 dias (período neonatal), tendo como causas associadas à gestação e ao recém-nascido como asfixia no parto e sepse neonatal (UNICEF, 2019, GONÇALVES AC, et al., 2015; OLIVEIRA CM, et al., 2016; MAIA LTS, et al., 2020).

Apesar da redução da $\mathrm{Ml}$ em mais de dois terços dos óbitos no Brasil nos últimos anos, as causas básicas de mortes em crianças ainda têm ocorridos por etiologias evitáveis e preveníveis (FRANÇA EB, et al., 2017). Os achados encontrados em Porto Velho indicam que as infecções relacionadas ao período perinatal, continuam elevadas, a exemplo de outras cidades da região Norte. Estudo realizado em uma maternidade de referência no Pará, no ano de 2016, identificou como principais causa de óbitos infantis a sepse, a prematuridade e distúrbios respiratórios nos recém-nascidos (BEZERRA NF, et al., 2016).

Mesmo em regiões desenvolvidas do país, nos anos de 2018, a sepse foi responsável por $30,7 \%$ dos 745 óbitos no período neonatal (7,5/1.000 NV) estando a sepse envolvida em 2,3/1.000 NV. Tal advento tem associação com os cuidados pré-natais relacionados a pré-eclâmpsia e infecção do trato urinário, o que demonstra falhas na atenção adequada à gestante, seja pelo baixo número de consulta ou pela má qualidade do pré-natal no âmbito da Atenção Primária à Saúde, a ordenadora do cuidado em todos os ciclos de vida (ALVES JB, et al., 2018). 
Conclui-se que a adequada atenção ao pré-natal, parto e puerpério, são ações essenciais para reduzir a MI, especialmente no primeiro ano de vida. Assim, é necessário melhorar a qualidade das ações de prevenção, diagnóstico e tratamento precoce das infecções no pré-natal, parto e nascimento nos primeiros dias de vida. Não obstante, uma gestão local atuante é fundamental para a redução da mortalidade neonatal (MOREIRA KFA, et al., 2014; MOREIRA KFA, et al., 2017).

Ainda que os achados desse estudo corroborem com outras análises, as limitações estão vinculadas aos dados secundários, suscetíveis pelo preenchimento incompleto ou incorreto de variáveis do SINASC e SIM. Por outro lado, são fontes de fácil acesso, com tamanho amostral considerável, e, portanto, possibilita a inferência dos aspectos analisados com finalidade de comparar a outros contextos.

Os resultados da presente investigação na capital poderão auxiliar o monitoramento do óbito infantil no momento em que a gestão municipal está realizando a planificação no âmbito do Sistema Único de Saúde (SUS). O estudo pode ser útil também à academia, aproximando o ensino-serviço-comunidade, por meio de práticas interprofissionais na rede de atenção à saúde local.

\section{CONCLUSÃO}

Em Porto Velho, de 2012 a 2017, o óbito infantil foi maior no período neonatal precoce por causas evitáveis relacionadas à adequada atenção ao feto/recém-nascido e à mulher na gestação. A maioria dos óbitos por septicemia bacteriana não especificada no neonato, reflete graves falhas no pré-natal, no manejo do bebê no parto e após o nascimento, mas, sobretudo nos primeiros seis dias de vida. É imprescindível qualificar a assistência materno-infantil, sobretudo na Atenção Primária à Saúde, valorizando profissionais que atuam no ciclo gravídico-puerperal. É preciso também qualificar médicos no preenchimento das notificações para melhorar a vigilância do óbito infantil. Sugere-se avaliar a qualidade do pré-natal para identificar os obstáculos no cuidado à gestante bem como a assistência realizada no momento do parto.

\section{REFERÊNCIAS}

1. ALVES JB, et al. Sepse neonatal: mortalidade em um município do sul do Brasil, 2000 a 2013. Revista Paul Pediartr, 2018; 36(2): 132-40.

2. ALKEMA L, et al. National, regional and global sex ratios of infant, child and under-5 mortality and indentification of countries with outlying ratios: a systematic assessment. Lancet Global Health, 2014; 2(9): 521-30.

3. ASSOCIÇÃO BRASILEIRA DE SAÚDE COLETIVA (ABRASCO). 2018. Especial ABRASCO sobre o aumento da mortalidade infantil e materna no Brasil. Disponível em: https://www.abrasco.org.br/site/outrasnoticias/institucional/especial-abrasco-sobre-o-aumento-da-mortalidade-infantil-e-materna-no-brasil/36777/.Acesso em 23 jun. 2019.

4. BATISTA CB, et al. controles, Acesso e utilização de serviços de saúde como fatores associados à mortalidade neonatal no Norte, Nordeste e Vale do Jequitinhonha, Brasil. J Pediatr, 2018; 94(3): 293-99.

5. BEZERRA NF, et al. Fatores relacionados à mortalidade neonatal. Rev Enferm UFPE online, 2016; 10(11): 3951-9.

6. BRASIL. 2016. Ministério da Saúde. Coordenação Geral de Informação e Análise Epidemiológica. Painel de Monitoramento da Mortalidade Infantil e Fetal. Disponível em: http://www2.datasus.gov.br/DATASUS/index.php?area=0205\&id=693 8\&VObj=http://tabnet.datasus.gov.br/cgi/deftohtm.exe?sim/cnv/inf10.Acesso em: 10 ago. 2020.

7. BRASIL. 2015. Ministério da cidadania. Secretária Especial de Desenvolvimento Social. Mortalidade infantil caiu $73 \%$ em 25 anos. Disponível em: http://mds.gov.br/area-de-imprensa/noticias/2015/setembro/mortalidade-infantil-nobrasil-caiu-73-em-25-anos\#anavigation.Acesso em: 17 jul. 2019.

8. BRASIL. 2017. Ministério do planejamento, desenvolvimento e gestão. Instituto brasileiro de geografia e estatística. Diretoria de pesquisas. Coordenação de população e indicadores sociais. Tábua completa de mortalidade para o Brasil. Breve análise da evolução da mortalidade no Brasil. Disponível em:<ftp://ttp.ibge.gov.br/Tabuas_Completas_de_Mortalidade/Tabuas_Completas_de_Mortalidade_2016/tabua_de_ mortalidade_2016_analise.pdf. Acesso em: 23 jun. 2019.

9. CALDAS ADR, et al. Mortalidade infantil segundo cor ou raça com base no Censo Demográfico de 2010 e nos sistemas nacionais de informação em saúde no Brasil. Cad. Saúde Pública, 2017; 33(7): e00046516.

10. CASTRO ECM. Mortality in the first $24 \mathrm{~h}$ of very low birth weight preterm infants in the Northeast of Brazil. Rev Paul Pediatr, 2016; 34(1): 106-13.

11. DIAS BAS, et al. Classificação da evitabilidade dos óbitos infantis: diferentes métodos, diferentes repercussões? Cad Saúde Pública, 2017; 33(5): e00125916.

12. FRANÇA EB, et al. Principais causas da mortalidade na infância no Brasil, em 1990 e 2015: estimativas do estudo de Carga Global de Doença. Rev Bras Epidemiol, 2017; 20(suppl. 1): 46-60. 
13. FILHO ACAA, et al. Aspectos epidemiológicos da mortalidade neonatal em capital do nordeste do Brasil. Rev Cuid, 2017; 8(3): 1767-76.

14. GBD 2016. Causes of Death Collaborators. Global, regional, and national age-sex specific mortality for 264 causes of death, 1980-2016: a systematic analysis for the Global Burden of Disease Study 2016. Lancet, 2019; 360(10106): e38.

15. GONÇALVES AC, et al. Tendência de mortalidade neonatal na cidade de Salvador (Bahia-Brasil), 1996-2012. Rev Bras Saúde Matern Infant, 2015; 14(3): 337-47.

16. IBGE. 2013. Instituto Brasileiro de Geografia e Estatística. Brasília (DF): IBGE; c2020. Disponível em: https://brasilemsintese.ibge.gov.br/populacao/taxas-de-mortalidade-infantil.html.Aceso em: 27 mai. 2020.

17. IBGE. 2017. Instituto Brasileiro de Geografia e Estatística. Brasília (DF): IBGE; c2020. Disponível em: https://cidades.ibge.gov.br/brasil/ro/porto-velho/panorama.Acesso em: 15 jun. 2020.

18. KROPIWIEC MV, et al. Fatores associados à mortalidade infantil em município com índice de desenvolvimento humano elevado. Rev Paul Pediatr, 2017; 35(4): 391-8.

19. LANSKY S, et al. Pesquisa Nascer no Brasil: perfil da mortalidade neonatal e avaliação da assistência à gestante e ao recém-nascido. Cad Saúde Pública, 2014; 30(esp): 192-207.

20. LIMA JC, et al. Estudo de base populacional sobre mortalidade infantil. Cien Saude Colet, 2017; 22(3): $931-39$.

21. MALTA DC, et al. Atualização da lista de causas de mortes evitáveis por intervenções do Sistema Único de Saúde do Brasil. Epidemiol. Serv. Saúde, 2010; 19(2): 173-6.

22. MALTA DC, et al. Mortes evitáveis na infância, segundo ações do Sistema Único de Saúde, Brasil. Rev Bras Epidemiol, 2019; 22(esp): 1-15.

23. MAIA LTS, et al. Determinantes individuais e contextuais associados à mortalidade infantil nas capitais brasileiras: uma abordagem multinível. Cad. Saúde Pública, 2020; 36(2): e00057519.

24. MOREIRA KFA, et al. Mortalidade infantil nos últimos quinquênios em Porto Velho, Rondônia - Brasil. Rev. bras. crescimento desenvolv. Hum [Internet], 2014; 24(1): 86-92.

25. MOREIRA KFA, et al. Perfil e evitabilidade de óbito neonatal em um município da Amazônia legal. Cogitare Enferm [Internet], 2017; 22(2): e48950.

26. MIGOTO MT, et al. Mortalidade neonatal precoce e fatores de risco: estudo caso-controle no Paraná. Rev Bras Enferm, 2018 71(5): 2675-83.

27. OLIVEIRA MND, et al. Características dos óbitos infantis em um município de médio porte da região nordeste do Brasil. J. Health Biol Sci, 2017; 5(2): 160-64.

28. OLIVEIRA CM, et al. Mortalidade infantil: tendência temporal e contribuição na vigilância do óbito. Acta Paul Enferm, 2016; 29(3): 282-90.

29. ORGANIZAÇÃO PAN-AMARICANA DE SAÚDE (OPAS). 2016. ORGANIZAÇÃO MUNDIAL DE SAÚDE (OMS). Américas alcançam quase todas as metas de saúde dos Objetivos do Desenvolvimento do Milênio. Disponível em: https://www.paho.org/hq/dmdocuments/2016/CD55-INF-5-e.pdf.Acesso em: 17 jul. 2019.

30. ORGANIZAÇÃO DAS NAÇÕES UNIDAS (ONU). 2015. Relatório sobre os Objetivos de Desenvolvimento do Milénio. Disponível em: https://www.unric.org/pt/images/stories/2015/PDF/MDG2015_PT.pdf.Acesso em: 28 abr. 2018.

31. RÊGO MGS, et al. Óbitos perinatais evitáveis por intervenções do Sistema Único de Saúde do Brasil. Rev Gaúcha Enferm, 2018; 39:e3017-0083.

32. SARTORELLI AP, et al. Fatores que contribuem para a mortalidade infantil utilizando a mineração de dados. Saúde e Pesquisa, 2017; 10(1): 33-41.

33. UNITED NATIONS CHILDREN'S FUDS (UNICEF). 2015. WORLD HEALTH ORGANIZATION (WHO). Levels \& Trends in Child Mortality: 2015. Report Disponivel em: https://reliefweb.int/sites/reliefweb.int/files/resources/IGME_Report_Final2.pdf.Acessoem: 17 jul. 2019.

34. UNITED NATIONS CHILDREN'S FUND (UNICEF). 2019. Levels \& Trends in Child Mortality, Report 2019: Estimates developed by the UN Inter-agency Group for Child Mortality Estimation. Disponível em:< https://data.unicef.org/resources/levels-and-trends-in-child-mortality/>.Acesso em: 27 mai. 2020.

35. VILANOVA CS, et al. The relationship between the different low birth weight strata of newborns with infant mortality and the influence of the main health determinants in the extreme south of Brazil. Populations Health Metrics, 2019; 17(15): 1-12.

36. VIDAL E SILVA SMC, et al. Factors associated with preventable infant death: a multiple logistic regression. Rev. Saúde Publica, 2018; 52(32): 1-11.

37. WANG H, et al. Global, regional, and national levels of neonatal, infant, and under-5 mortality during 1990-2013: a systematic analysis for the Global Burden of Disease Study 2013. The Lancet, 2014; 384:957-79. 